geget (2019) Volume 14 - Issue1

Original Article

\title{
Urinary CD25 as a Biomarker of Lupus Nephritis Activity in Pediatrics
}

\author{
Doaa M. Tawfeek', Mohammed M. Abdel Salam', Eslam S. Mobasher', \\ Naglaa A. Khalifa ${ }^{2}$ and Maher El-Shafaei ${ }^{3}$ \\ 1- Departments of Pediatrics, Faculty of Medicine, Zagazig University \\ 2- Clinical Pathology, Faculty of Medicine, Zagazig University \\ 3- Microbiology and Immunology, Faculty of Medicine, Zagazig University
}

\begin{abstract}
Background

Lupus nephritis is one of the most serious manifestations of Systemic lupus erythematosus. Proteinuria, complement level, anti-dsDNA and creatinine are the most widely used to assess activity.
\end{abstract}

\section{Aim of Work}

The aim of this study was to assess the relationship of urinary s CD25 with lupus nephritis activity as a noninvasive biomarker in children.

\section{Patients and Methods}

The study was conducted on 30 patients divided into 2 groups; Group I: 20 patients of SLE, subdivided into 2 subgroups according to presence of lupus nephritis and Group II: 10 healthy subjects as a control group. Urinary sCD25 was measured in both groups.

\section{Results}

Urinary SCD25 was significantly higher in active LN in comparison to inactive and controls. Urinary s CD25 level was correlated with SLE activity, proteinuria and blood urea.

Conclusion Urinary sCD25 is a useful noninvasive technique for assessment of lupus nephritis as it shows a good correlation with some clinical and laboratory parameters of disease relapse.

Keywords: SLE, CD25, Nephritis, Children

Correspondence: Mohammed M. Abdel Salam, Faculty of Medicine, Zagazig University, Hay El-Zhour, Zagazig City, Sharqia Governorate, Egypt.

Email: Mohammedabdelsalam732@yahoo.com

geget : The Journal of the Egyptian Society of Pediatric Nephrology and Transplantation (ESPNT) geget https://geget.journals.ekb.eg/ Published by ESPNT http://espnt.net/ Cohosted by Egyptian Knowledge Bank https://www.ekb.eg 


\section{Introduction}

Systemic lupus erythematosus (SLE) is life long, life-limiting, multi-systemic autoimmune disease [1], whose etiology and pathogenesis are incompletely understood [2].

Glomerulonephritis is one of the most serious manifestations of SLE. Despite the improvement in the medical care of the SLE in the past two decades, the prognosis of lupus nephritis (LN) remains unsatisfactory [3].

The current most widely used biomarkers for the early detection of chronic kidney disease or acute kidney injury are proteinuria, serum creatinine, and blood urea nitrogen. All of these are less than optimal and tend to focus attention on later stages of injury when therapies may be less effective [4].

Renal biopsy is the gold standard for providing information on the histological classes of $\mathrm{LN}$ and relative degree of activity and chronicity in the glomeruli. However, it is invasive and serial biopsies are required which is impractical in monitoring LN [3].

Increased $\mathrm{sCD} 25$ receptor expression is associated with increased $\mathrm{T}$-cell and B-cell activation and correlate with autoimmune disease. Patients with LN shed sCD25 in the urine, and this may act as a surrogate marker of T-cell activation in the kidney [5].

Urine is an excellent noninvasive resource to be utilized in investigating local immunopathogenesis of LN. Urinary CD25 was shown to be a sensitive and specific biomarker of renal SLE flare [5].

\section{Aim of work}

The purpose of this study was to assess the relationship of urinary CD25 with disease activity in children with lupus nephritis as a noninvasive biomarker.

\section{Patients and methods}

This cross sectional study was conducted at Pediatric Nephrology Unit, Zagazig University Hospitals during 8 months from September 2015 till April 2016. This study passed the Ethical Committee issue and consents for subject were taken.

Subjects:This study was carried out on 30 patients and divided into two groups:

Group I (patient group): This group was subdivided into: Subgroup A: This subgroup included 10 patients with SLE without clinical and laboratory picture of renal disease not in activity. There were $5(50 \%)$ males and $5(50 \%)$ females; their ages range from 8 to 14 years.

Subgroup B: This subgroup included 10 patients with SLE with clinically, laboratory and biopsy diagnosed renal diseased in activity and after remission. There were 2 (20\%) males and $8(80 \%)$ females, their ages range from 8 to 14 years.

All patients fulfilled at least four of the American College of Rheumatology preliminary criteria for diagnosis of SLE [6]
Group II: This group included 10 children age- and sexmatched healthy subjects as a control group. There were 5 $(50 \%)$ males and $5(50 \%)$ females.

\section{Inclusion criteria:}

- Age from 8 to 14 years old.

- Cases of active lupus nephritis.

Exclusion criteria:

- Patients with End-Stage Renal Disease (ESRD) or had undergone renal transplantation.

- Patients in whom a renal biopsy could not be performed.

- Known cases of lupus nephritis not in active disease.

Methods: All groups were subjected to:

1. Full history taking with special emphasis on disease activity in SLE patients measured by Systemic Lupus Erythematosus Disease Activity Index (SLEDAI) and laying stress on age, duration of the disease, urinary symptoms, SLE manifestations (e.g. joint pains, rash, cutaneous photosensitivity and CNS symptoms including seizures), symptoms of hypertension as vomiting, headache, blurred vision and type of therapy received by patient.

2. Thorough clinical examination, including vital signs and anthropometric measurements (weight and height), skin rash distribution, joint affection, chest and heart examination, abdominal examination and CNS examination.

3. Data about lupus nephritis:
a. Presence or absence.
b. Clinical presentation.
c. Laboratory evidence.
d. Renal biopsy.

4. Laboratory testing:

a. Serum creatinine and blood urea nitrogen (BUN).

b. Urine analysis, urinary protein to creatinine ratio.

c. Complete blood count.

d. Erythrocyte sedimentation rate (ESR).

e. Anti-DNA (deoxyribonucleic acid) employing indirect immunofluorescent test.

f. Complement 3 and 4 levels by radio immunodiffusion.

5. $\mathrm{sCD} 25$ in urine was determined using Enzyme-Linked Immunosorbent Assay (ELISA).

Aseptically urine was collected and stored at $-20^{\circ} \mathrm{C}$. The microtiter plate provided in this kit has been precoated with an antibody specific to IL-2 receptor. Samples are then added to microtiter plate wells with conjugated polyclonal antibody preparation. The color change is measured spectrophotometrically at a wave length of $450 \pm 2 \mathrm{~nm}$ [7].

\section{Statistical analysis}

All data were collected, tabulated and statistically analyzed using SPSS 22.0 for Windows (SPSS Inc., Chicago, IL, USA) and MedCalc 13 for Windows (MedCalc Software bvba, Ostend, Belgium). 


\section{Results}

This study included 20 patients with SLE; 7 males and 13 females. As regard sex distribution between 30 patients, $40 \%$ were male and $60 \%$ were female. There was no significant difference regarding age and sex between groups. There is a significant increase in weight in cases than control group (table 1).

The most common presenting symptom in our SLE cases is joint pain $(85 \%)$, followed with urinary symptoms and skin rash (50\%) (table 2).

$30 \%$ of SLE cases were treated with steroids alone, while $25 \%$ of cases were treated with steroids and cyclophosamide (table 3).
There is a significant increase in urinary CD25 in SLE cases with active nephritis in comparison to healthy control and SLE cases without nephritis (figure 1).

There is a significant difference between SLE without nephritis, SLE with inactive nephritis and SLE with active nephritis regarding to UPR/UCR ratio, USCD25, C3, C4, and anti-dsDNA (table 4).

There is no correlation between USCD25 and (C3, $\mathrm{C} 4$ ), but there is a positive significant correlation with antidsDNA and SLEDAI (table 5).

Urinary CD25 is the most sensitive and specific in discriminating between active lupus nephritis from inactive lupus nephritis at cutoff value of $>470 \mathrm{pg} / \mathrm{mg}$ by ROC curve (table 6).

Table 1: Comparison between SLE cases and control as regard demographic data, anthropometric measurements and laboratory data.

\begin{tabular}{|c|c|c|c|c|c|c|}
\hline \multirow[t]{2}{*}{ Demographic data } & \multicolumn{2}{|c|}{$\begin{array}{c}\text { Group I } \\
\text { (SLE cases) } \\
(\mathbf{n}=\mathbf{2 0}) \\
\end{array}$} & \multicolumn{2}{|r|}{$\begin{array}{c}\text { Group II } \\
\text { (control) } \\
(\mathbf{n}=\mathbf{1 0}) \\
\end{array}$} & \multirow[t]{2}{*}{ Test } & \multirow[t]{2}{*}{ p-value (significance) } \\
\hline & No & $\%$ & No & $\%$ & & \\
\hline \multicolumn{7}{|l|}{ Gender } \\
\hline Male & 7 & 35 & 5 & 50 & \multirow{2}{*}{0.625} & \multirow{2}{*}{$\begin{array}{c}0.461 \\
(\mathrm{NS})\end{array}$} \\
\hline Female & 13 & 65 & 5 & 50 & & \\
\hline \multicolumn{7}{|l|}{ Age (years) } \\
\hline Mean \pm SD & \multicolumn{2}{|c|}{$11.5 \pm 1.73$} & \multicolumn{2}{|r|}{$10.3 \pm 2.75$} & $1.26^{*}$ & \multirow{2}{*}{$\begin{array}{l}0.23 \\
(\mathrm{NS})\end{array}$} \\
\hline Median (range) & \multicolumn{2}{|c|}{$12(8-14)$} & \multicolumn{2}{|r|}{$10.5(6-14)$} & & \\
\hline Weight(kg) & & & & & & \\
\hline Mean \pm SD & \multicolumn{2}{|c|}{$37.15 \pm 7.48$} & \multicolumn{2}{|r|}{$27.9 \pm 6$} & 3.39 & \multirow{2}{*}{$\begin{array}{c}0.002 \\
(\mathrm{~S})\end{array}$} \\
\hline Median (range) & \multicolumn{2}{|c|}{$37(25-52)$} & \multicolumn{2}{|r|}{$28.5(18-35)$} & & \\
\hline \multicolumn{7}{|l|}{ Height(cm) } \\
\hline Mean \pm SD & \multicolumn{2}{|c|}{$138.8 \pm 15.23$} & \multicolumn{2}{|r|}{$142.2 \pm 9.48$} & 0.646 & \multirow{2}{*}{$\begin{array}{l}0.53 \\
(\mathrm{NS})\end{array}$} \\
\hline Median (range) & \multicolumn{2}{|c|}{$139(117-160)$} & \multicolumn{2}{|r|}{$145(126-155)$} & & \\
\hline \multicolumn{7}{|l|}{ Hemoglobin (g/dl) } \\
\hline Mean \pm SD & \multicolumn{2}{|c|}{$11.24 \pm 0.86$} & \multicolumn{2}{|r|}{$11.83 \pm 0.91$} & -1.719 & \multirow{2}{*}{$\begin{array}{l}0.097 \\
(\mathrm{NS})\end{array}$} \\
\hline Median (range) & \multicolumn{2}{|c|}{$11.25(9.8-13)$} & \multicolumn{2}{|r|}{$11.85(10.5-13)$} & & \\
\hline \multicolumn{7}{|l|}{ Urea $(\mathrm{mg} / \mathrm{dl})$} \\
\hline Mean \pm SD & \multicolumn{2}{|c|}{$21.45 \pm 5.2$} & \multicolumn{2}{|r|}{$17.2 \pm 3.7$} & -2.4 & 0.015 \\
\hline Median (range) & & & & $11.5(13-23)$ & & \\
\hline Creatinine (mg/dl) & & & & & & \\
\hline Mean \pm SD & & & & $0.76 \pm 0.25$ & 2.851 & 0.008 \\
\hline Median (range) & & & & $0.75(0.5-1)$ & & (S) \\
\hline
\end{tabular}

*Independent samples Student's t-test - Chi-square test $\quad$-p-value $<0.05$ is significant 
Table 2: Clinical picture of SLE $(n=20)$.

\begin{tabular}{|c|c|c|}
\hline \multirow{2}{*}{ Symptoms } & \multicolumn{2}{|c|}{$\begin{array}{c}\text { SLE cases } \\
(\mathrm{n}=\mathbf{2 0})\end{array}$} \\
\hline & No & $\%$ \\
\hline Urinary symptoms & 10 & 50 \\
\hline Joint pain & 17 & 85 \\
\hline Rash & 10 & 50 \\
\hline Skin rash distribution(face) & 10 & 50 \\
\hline Cutaneous photosensitivity & 0 & 0 \\
\hline CNS symptoms & 0 & 0 \\
\hline Convulsion & 0 & 0 \\
\hline Hypertension & 5 & 25 \\
\hline \multicolumn{3}{|l|}{ Chest examination } \\
\hline Pleurisy & 3 & 15 \\
\hline \multicolumn{3}{|l|}{ Heart examination } \\
\hline Pericarditis & 2 & 10 \\
\hline Abdominal examination & 0 & 0 \\
\hline \multicolumn{3}{|l|}{ CNS examination } \\
\hline Seizure/psychosis & 0 & 0 \\
\hline
\end{tabular}

Table 3: Treatment of SLE cases $(n=20)$.

\begin{tabular}{|l|l|l|}
\hline \multirow{2}{*}{ Treatment } & \multicolumn{2}{l|}{$\begin{array}{l}\text { SLE cases } \\
(\mathbf{n = 2 0})\end{array}$} \\
\cline { 2 - 3 } & No & \% \\
\hline Steroid & 6 & 30 \\
\hline Steroids + cyclophosphamide & 5 & 25 \\
\hline Steroids + Azathioprine & 4 & 20 \\
\hline Steroids + Hydroxychloroquine & 5 & 25 \\
\hline
\end{tabular}

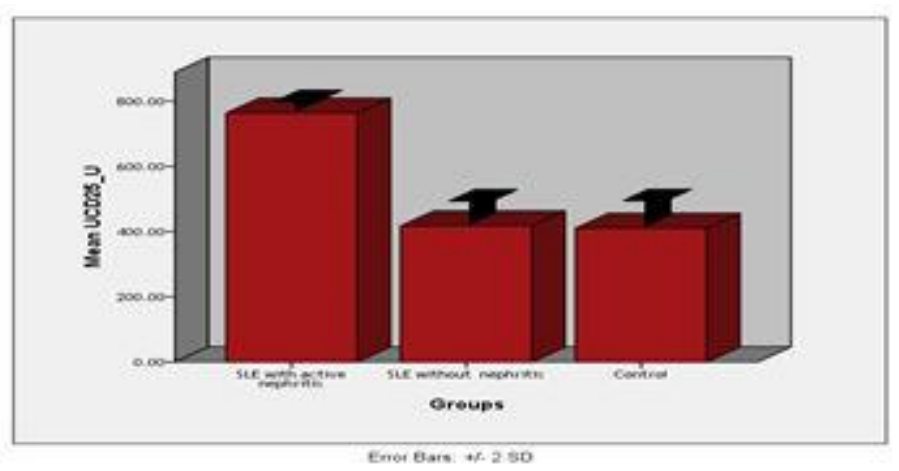

Figure 1: Comparison between healthy control, SLE with active nephritis and SLE without nephritis as regard UCD25 
Table 4: Comparison between SLE without nephritis, SLE with inactive nephritis and SLE with active nephritis as regard markers of SLE.

\begin{tabular}{|c|c|c|c|c|c|}
\hline \multirow[b]{2}{*}{ Markers } & \multirow{2}{*}{$\begin{array}{c}\text { Subgroup A } \\
\begin{array}{c}\text { SLE without } \\
\text { nephritis }\end{array} \\
\end{array}$} & \multicolumn{2}{|c|}{ Subgroup B } & \multirow[b]{2}{*}{ Test } & \multirow[b]{2}{*}{ p-value } \\
\hline & & $\begin{array}{c}\text { SLE with } \\
\text { inactive nephritis }\end{array}$ & $\begin{array}{c}\text { SLE with } \\
\text { active nephritis }\end{array}$ & & \\
\hline $\begin{array}{c}\text { UP/creatinine ratic } \\
\text { Mean } \pm \text { SD } \\
\text { Median (range) }\end{array}$ & $\begin{array}{c}0.14 \pm 0.03 \\
0.14(0.1-0.2)\end{array}$ & $\begin{array}{c}0.16 \pm 0.03 \\
0.16(0.1-0.2)\end{array}$ & $\begin{array}{c}3.09 \pm 1.54 \\
3.75(0.18-4.1)\end{array}$ & 9.8 & $<0.001 * *$ \\
\hline $\begin{array}{c}\text { Anti-dsDNA } \\
\text { Mean } \pm \text { SD } \\
\text { Median (range) } \\
\end{array}$ & $\begin{array}{c}94.2 \pm 22.07 \\
92.5(66-130)\end{array}$ & $\begin{array}{c}77.8 \pm 10.07 \\
75(65-93) \\
\end{array}$ & $\begin{array}{c}129.8 \pm 26.7 \\
130.5(85-165)\end{array}$ & 7.3 & $<0.001 * *$ \\
\hline $\begin{array}{c}\text { ESR }^{\text {st }} \mathbf{h} \\
\text { Mean } \pm \text { SD } \\
\text { Median (range) } \\
\end{array}$ & $\begin{array}{c}19.6 \pm 15.44 \\
15(5-45) \\
\end{array}$ & $\begin{array}{c}17.5 \pm 15.27 \\
7(4-40) \\
\end{array}$ & $\begin{array}{c}23 \pm 15.45 \\
30(4-42) \\
\end{array}$ & 0.34 & 0.71 \\
\hline $\begin{array}{c}{\text { ESR } 2^{\text {nd }} \mathbf{h}} \\
\text { Mean } \pm \text { SD } \\
\text { Median (range) }\end{array}$ & $\begin{array}{c}31.7 \pm 23.1 \\
23.5(11-70)\end{array}$ & $\begin{array}{l}32.3 \pm 24.67 \\
14.5(12-65)\end{array}$ & $\begin{array}{c}46.9 \pm 29.58 \\
58(13-80)\end{array}$ & 1.17 & 0.28 \\
\hline $\begin{array}{c}\text { C3 }(\mathbf{n g} / \mathbf{d l}) \\
\text { Mean } \pm \text { SD } \\
\text { Median (range) }\end{array}$ & $\begin{array}{l}68.3 \pm 35.8 \\
63(28-113)\end{array}$ & $\begin{array}{l}123.4 \pm 27.52 \\
125(80-170)\end{array}$ & $\begin{array}{c}37.6 \pm 5.73 \\
35.5(31-47)\end{array}$ & 11.4 & $<0.001 * *$ \\
\hline $\begin{array}{c}\text { C4 (ng/dl) } \\
\text { Mean } \pm \text { SD } \\
\text { Median (range) }\end{array}$ & $\begin{array}{c}23.4 \pm 12.5 \\
21.5(10-40)\end{array}$ & $\begin{array}{c}28.6 \pm 5.52 \\
27.5(20-35)\end{array}$ & $\begin{array}{c}10.7 \pm 3.23 \\
11(6-16) \\
\end{array}$ & 8.3 & $0.0006^{* *}$ \\
\hline $\begin{array}{c}\text { US CD25 } \\
\text { Mean } \pm \text { SD } \\
\text { Median (range) }\end{array}$ & $\begin{array}{c}417.2 \pm 35 \\
412(372-473)\end{array}$ & $\begin{array}{l}414.5 \pm 43.55 \\
420(347-470)\end{array}$ & $\begin{array}{c}763.2 \pm 14.93 \\
762.5(743-785)\end{array}$ & 89.7 & $<0.001 * *$ \\
\hline $\begin{array}{c}\text { SLE DAI } \\
\text { Mean } \pm \text { SD } \\
\text { Median (range) } \\
\end{array}$ & $\begin{array}{c}1.4 \pm 0.3 \\
1(0-2) \mathrm{q} \mathrm{q}\end{array}$ & $\begin{array}{l}2.5 \pm 0.8 \\
2.4(2-4)\end{array}$ & $\begin{array}{c}15.8 \pm 0.4^{*} \\
16(10-20)\end{array}$ & 8.8 & $<0.001 * *$ \\
\hline
\end{tabular}

UsCD25: urinary soluble CD25, Up/creatinine ratio: protein/urine creatinine ratio. SLE DAI: SLE disease activity index 
Table 5: Correlation between study variables in SLE cases $(n=20)$.

\begin{tabular}{|c|c|c|c|c|}
\hline \multirow{2}{*}{ Variables } & \multicolumn{2}{|c|}{ Upr/Ucr ratio } & \multicolumn{2}{|c|}{ UsCD25 } \\
\hline & $\mathbf{r}$ & p-value (Sig.) & $\mathbf{r}$ & p-value (Sig.) \\
\hline Age (years) & -0.029 & 0.904 (NS) & +0.196 & 0.408 (NS) \\
\hline Weight $(\mathrm{kg})$ & +0.001 & 0.996 (NS) & +0.389 & $0.046(\mathrm{~S})^{*}$ \\
\hline Height (cm) & +0.016 & 0.945 (NS) & +0.229 & $0.156(\mathrm{NS})$ \\
\hline Duration (years) & -0.073 & 0.760 (NS) & +0.262 & 0.265 (NS) \\
\hline SLE DAI & 0.421 & $0.002(\mathrm{~S})^{*}$ & 0.434 & $0.001(\mathrm{HS})^{*}$ \\
\hline Hemoglobin (g/dl) & +0.046 & 0.849 (NS) & +0.027 & $0.910(\mathrm{NS})$ \\
\hline Urea $(\mathrm{mg} / \mathrm{dl})$ & -0.036 & $0.880(\mathrm{NS})$ & +0.476 & $0.0005(\mathrm{HS})^{*}$ \\
\hline Creatinine (mg/dl) & +0.277 & $0.101(\mathrm{NS})$ & -0.107 & $0.654(\mathrm{NS})$ \\
\hline ESR 1st (mm/hr) & +0.209 & 0.100 (NS) & -0.177 & $0.456(\mathrm{NS})$ \\
\hline ESR 2nd (mm/hr) & +0.155 & 0.149 (NS) & -0.037 & 0.876 (NS) \\
\hline Anti-dsDNA (IU/ml) & +0.396 & $0.042(\mathrm{~S})^{*}$ & +0.402 & $0.009(\mathrm{~S})^{*}$ \\
\hline C3 (ng/dl) & -0.092 & 0.698 (NS) & -0.023 & 0.925 (NS) \\
\hline $\mathrm{C} 4$ (ng/dl) & -0.284 & 0.224 (NS) & +0.064 & $0.788(\mathrm{NS})$ \\
\hline Upr/Ucr ratio & & & +0.415 & $0.003(\mathrm{~S})^{*}$ \\
\hline
\end{tabular}

r Spearman'ls rank correlation coefficient

$\mathrm{p}<0.05$ is significant SLE DAI: SLE disease activity index

Table 6: Diagnostic performance of Upr/Ucr ratio, anti-dsDNA, C3, C4 and UsCD25 in discriminating between active lupus nephritis from inactive lupus nephritis (ROC curve analysis).

\begin{tabular}{|c|c|c|c|c|c|c|}
\hline Cutoff values & $\begin{array}{c}\text { SN\% } \\
(95 \% \mathrm{CI})\end{array}$ & $\begin{array}{c}\text { SP\% } \\
(95 \% \mathrm{CI})\end{array}$ & $\begin{array}{l}\text { PPV\% } \\
(95 \%)\end{array}$ & $\begin{array}{l}\text { NPV\% } \\
(95 \% \text { CI })\end{array}$ & $\begin{array}{l}\text { Accuracy } \\
(95 \% \text { CI })\end{array}$ & $\begin{array}{l}\text { AUROC } \\
(95 \% \text { CI })\end{array}$ \\
\hline $\begin{array}{c}\text { Upr/Ucr ratio } \\
>0.2\end{array}$ & $\begin{array}{c}80 \% \\
(44.4-97.5)\end{array}$ & $\begin{array}{r}100 \% \\
(69.2-100)\end{array}$ & $\begin{array}{c}100 \% \\
(63.1-100)\end{array}$ & $83.3 \%(49.9-98.2)$ & $\begin{array}{c}90 \% \\
(56.8-98.8)\end{array}$ & $\begin{array}{c}0.94 * \\
(0.737-0.997)\end{array}$ \\
\hline $\begin{array}{c}\text { Anti-dsDNA } \\
>93 \mathrm{IU} / \mathrm{ml}\end{array}$ & $\begin{array}{c}80 \% \\
(44.4-97.5)\end{array}$ & $\begin{array}{c}100 \% \\
(69.2-100)\end{array}$ & $\begin{array}{c}100 \% \\
(63.1-100)\end{array}$ & $83.3 \%(49.9-98.2)$ & $\begin{array}{c}90 \% \\
(56.8-98.8)\end{array}$ & $\begin{array}{c}0.95^{++} \\
(0.751-0.999)\end{array}$ \\
\hline $\begin{array}{c}\mathrm{C3} \\
\leq 47 \mathrm{ng} / \mathrm{dl}\end{array}$ & $\begin{array}{c}100 \% \\
(69.2-100)\end{array}$ & $\begin{array}{c}100 \%(69.2- \\
100)\end{array}$ & $\begin{array}{c}100 \% \\
(69.2-100)\end{array}$ & $\begin{array}{c}100 \% \\
(69.2-100)\end{array}$ & $\begin{array}{c}100 \% \\
(69.2-100)\end{array}$ & $\begin{array}{c}1^{*} \\
(0.832-1)\end{array}$ \\
\hline $\begin{array}{c}\mathrm{C4} \\
\leq 16 \mathrm{ng} / \mathrm{dl}\end{array}$ & $\begin{array}{c}100 \% \\
(69.2-100)\end{array}$ & $\begin{array}{c}100 \%(69.2- \\
100)\end{array}$ & $\begin{array}{c}100 \% \\
(69.2-100)\end{array}$ & $\begin{array}{c}100 \% \\
(69.2-100)\end{array}$ & $\begin{array}{c}100 \% \\
(69.2-100)\end{array}$ & $\begin{array}{c}1^{+} \\
(0.832-1)\end{array}$ \\
\hline $\begin{aligned} & \text { UsCD25 } \\
> & 470 \mathrm{pg} / \mathrm{mg}\end{aligned}$ & $\begin{array}{c}100 \% \\
(69.2-100)\end{array}$ & $\begin{array}{c}100 \\
(69.2-100)\end{array}$ & $\begin{array}{c}100 \\
(69.2-100)\end{array}$ & $\begin{array}{c}100 \\
(69.2-100)\end{array}$ & $\begin{array}{c}100 \\
(69.2-100)\end{array}$ & $\begin{array}{c}1^{+++} \\
(0.832-1)\end{array}$ \\
\hline
\end{tabular}

${ }^{*} \mathrm{p}<0.001(\mathrm{HS}) ;{ }^{++} \mathrm{p}<0.001(\mathrm{HS}) ;{ }^{+} \mathrm{p}<0.001(\mathrm{HS}) ;{ }^{+++} \mathrm{p}<0.001$ (HS) $\mathrm{p}<0.05$ is significant

ROC curve: Receiver Operating Characteristic curve; SN: Sensitivity; SP: Specificity; PPV: Positive Predictive Value; NPV: Negative Predictive Value; AUROC: Area Under Receiver Operating Characteristic curve; 95\% CI: 95\% Confidence Interval. 


\section{Discussion}

Systemic lupus erythematosus (SLE) is a prototypical, autoimmune, multisystem disease characterized by chronic inflammation in multiple organs [8].

SLE has a negative impact on quality of life and is associated with high health-care costs and significant productivity loss [9]. In consequence, SLE incurs a great burden on both the patient and society [10].

Juvenile-onset systemic lupus erythematosus (JSLE) is a typically has a more active disease course and in particular more renal involvement than disease presenting in adulthood. The renal biopsy is the gold standard in confirming the diagnosis and class of lupus nephritis (LN) [11].

Current laboratory markers for lupus nephritis such as proteinuria, urine protein-to-creatinine ratio, creatinine clearance, anti-dsDNA, and complement levels are unsatisfactory. They lack sensitivity and specificity for differentiating renal activity and damage in lupus nephritis. Significant kidney damage can occur before renal function is impaired and first detection by laboratory parameters. Flares of nephritis can occur without any observable and recent increase in the degree of proteinuria [3].

This study was conducted at Pediatric Nephrology Unit, Zagazig University Hospitals to investigate urinary level of sCD25 as a biomarker of disease activity of pediatric lupus nephritis using ELISA test. We aimed to determine whether urinary concentrations of $\mathrm{sCD} 25$ are biomarker of active renal disease in JSLE.

In our study, serum creatinine and hemoglobin data emerged as independent predictors of renal insufficiency, these results match with Howard and Austin [12] and do not match with Gaberella et al [13]. who stated that the occurrence of flares characterized by rapid increases in plasma creatinine was the strongest predictor of the eventual development of irreversible deterioration renal function.

In our study, urinary symptoms increased in SLE patients with active nephritis and decrease with patients without nephritis and these results match with Cameron [14] who stated that patients with lupus nephritis have abnormalities of urine or renal function early in their course, although up to $60 \%$ of adults and $80 \%$ of children may develop overt renal abnormalities later.

In our study, hypertension was found in nearly $50 \%$ of patients with nephritis and was not common, this matched with Cameron [14] who stated that hypertension is not overall more common in those with nephritis than in those without but as expected; those with more severe nephritis are more commonly hypertensive.

Our study showed that UsCD25 achieved a mean \pm SD of $763.2 \pm 14.93$ in SLE with active nephritis patients and a mean \pm SD of $414.5 \pm 43.55$ in SLE without lupus nephritis in comparison to healthy control $(410.3 \pm 39.6)$, p-value was $<0.001$, which indicates a high sensitivity of UsCD25 in detecting activity and remissions.

This matches with Chan et al. ${ }^{(15)}$ who stated that urinary sCD25 levels decreased in the AN group over one year with immunosuppressive treatment and reached the levels seen in inactive disease patients at one year, suggesting that this can be used to follow-up patients.

Higher urinary sCD25 in patients with active nephritis as compared with patients without nephritis suggest that there may be local activation of $\mathrm{T}$ cells in kidney [16].

Urinary sCD25 is a good marker of LN for follow up as it falls in patients with good response and stays raised or rises more when there is poor response or relapse [17].

Studies have indicated that Neutrophil GelatinaseAssociated Lipocalin (NGAL) might be a useful screening marker and is more predictive than complement or proteinuria. NGAL can detect impending renal or global flares but cannot discriminate against renal severity [18].

In our study, urinary CD25 level correlated well with SLE disease activity as measured by SLEDAI. In addition, urinary CD25 correlates positively with proteinuria, blood urea nitrogen level, so that urinary CD25 correlates with severity of nephritis, we concluded that the measurement of CD25 in urine may be useful for monitoring the severity of renal affection in SLE, and this matches with El-Shafey et al [18].

In our results, patients with active lupus nephritis had lower $\mathrm{C} 3$ and $\mathrm{C} 4$ than those with inactive LN, also significant higher level of urea levels, these results match with Terborg et al [19].

In our study, we observed significant correlation between UsCD25 with levels of anti-dsDNA antibodies and SLEDAI. In line with our data, Lin et al [20] reported a significant increase of UsCD25 in patients with active SLE, determined by the SLEDAI score, as compared to patients with inactive SLE. In contrast, Bonelli et al [21] and Zhang et al [22] observed no correlation between UsCD25 and disease activity, the complement levels.

\section{Study Limitations}

Our study is small sample size, longitudinal follow up of patients with active nephritis and measurement of urinary sCD25 levels. The limitations are lack of data on expression of CD25 in the kidney biopsy tissue, lack of other

T-cell biomarkers.

Conclusion and recommendations: Urinary $\mathrm{CD} 25 \geq 470 \mathrm{pg} / \mathrm{mg}$ is a useful noninvasive biomarker and the SLEDAI as a disease activity tool for the assessment of renal disease affection in patients with lupus nephritis, as it shows a good correlation with some clinical and laboratory parameters of disease relapse. Urinary CD25 can be used to follow patients with lupus nephritis beside other markers like C3, C4 and Up/Ucr with high sensitivity and specificity.

\section{Ethics approval and consent to participate}

This study protocol and the consents were approved and deemed sufficient by "The Postgraduate Clinical Research and Ethical Committee of Pediatric Department, Faculty of Medicine, Zagazig University." And Informed written consent was obtained in every case from their legal guardians. 


\section{Funding}

The authors declare that they didn't receive any financial support from agencies or others.

\section{Conflict of interest: No}

\section{Acknowledgements}

We would like to thank all patients and their family members for their valuable contributions to the study.

\section{References}

1- Berntsky S, Boivin JF and Joseph L. Mortality in systemic lupus erythematosus.

Arthritis Rheum; 2006, 54: 2550-2557.

2- Marks SD, Williams SJ and Tullus K Glomerular expression of monocyte chemoattractant protein-1 is predictive of poor prognosis in paediatric lupus nephritis. Oxford J Nephrology Dialysis

Transplantation; 2008, 23: 3521-3526.

3- Mok CC . Biomarkers for lupus nephritis: A critical appraisal.

J Biomed Biotechnol; 2010, 10: 1155-1170.

4- Rosner MH. Urinary biomarkers for the detection of renal injury. Adv Clin Chem; 2009, 49: 73-97.

5- Das L and Brunner HI. Biomarkers for renal disease in childhood.

Curr Rheumatol Rep; 2014, 11: 218-225.

6- Hochberg MC, Updating the American College of Rheumatology revised criteria for the classification of systemic lupus erythematosus.

Arthritis Rheum; 1997, 40(9): 1725-1727.

7- Stauber DJ, Debler EW and Wilson IA (2006): Crystal structure of the IL-2 signaling complex: Paradigm for a heterotrimeric cytokine receptor. Proc. Natl. Acad. Sci. USA; 103: 2788-2793.

8- Barbado J, Martin D and Vega. MCP-1 in urine as biomarker of disease activity in systemic lupus erythematosus. Cytokine Journal Homepage. 2012, www.elsevier.com/locate/issn/10434666 at Egyptian National Science Cytokine.

9- Slawsky KA, Fernandes AW and Fusfeld L. A structured literature review of the direct costs of adult systemic lupus erythematosus in the US. Arthritis Care Res (Hoboken); 2011, 63: 1224-32.

10-Lau CS and Mak A. The socioeconomic burden of SLE. Nat Rev Rheumatol; 2009, 5: 400-404.
11- Watson L, Midgley A and Pilkington C. Urinary monocyte chemoattractant protein 1 and alpha 1 acid glycoprotein as biomarkers of renal disease activity in juvenile-onset systemic lupus erythematosus. www.lup.sagepub.com at Egyptian National Science Lupus; 2012. 21: 496-501.

12- Howard A and Austin MD (1994): High-risk features of lupus nephritis: Importance of race and clinical and histological factors in 166 patients. National Institutes of Health, USA; 20: 892-1268.

13- Gabriella M, Silvana Q and Massimo M Nephritic flares are predictors of bad long-term renal outcome in lupus nephritis.

Kidney International;1996, 50: 2047-2053.

14- Cameron JS. Lupus nephritis.

J Am Soc Nephrol; 1999, 10: 413-424.

15- Chen HS, Wu MS and Yen TS. Soluble interleukin2 receptor in patients with glomerular diseases. Postgrad Med J; 1995, 71: 617-622.

16- Chan EY, Lau CS and Zola H. Expression of IL$2 \mathrm{R}, \mathrm{IL}-4 \mathrm{R}$ and IL-6R on peripheral blood lymphocytes in systemic lupus erythematosus and correlation with disease activity. J Clin Pathol; 1996, 49: 660-663.

17- Hinze C, Suzuki M and Gitelman MK . Neutrophil gelatinase-associated lipocalin is a predictor of the course of global and renal childhood-onset systemic lupus erythematosus disease activity.

Arthritis Rheum; 2009. 9: 2772-2781.

18- El-Shafey EM, El-Nagar GF and El-Bendary AS. Serum soluble interleukin-2 receptor alpha in systemic lupus erythematosus. Iran J Kidney Dis; 2008, 2: 80-85. 19- Terborg EJ, Horst GI and Limburg PC . Changes in plasma levels of interleukin-2 receptor in relation to disease exacerbations and levels of anti-dsDNA and complement in systemic lupus erythematosus. Clin Exp Immunol; 1990, 82: 21-26.

20- Lin C, Hsu HC and Chiang H .Improvement in histological and immunological change in steroid and immunosuppressive drug-resistant lupus nephritis by high-dose intravenous gamma globulin.

Nephron J; 2011， 53: 303-310.

21- Bonelli M, Goschl S and Bluml L.CD4+CD25Foxp3+ T cells: A marker for lupus nephritis? Arthritis Research and Therapy;2014, 16: 104.

22- Zhang B, Zhang $X$ and Tang FL.Clinical significance of increased CD4+CD25-Foxp3+ T cells in patients with new-onset systemic lupus erythematosus. Ann Rheum Dis; 2008, 67: 1037-1040.

\section{Declaration}

\section{Ethics approval and consent to participate}

This study protocol and the consents were approved and deemed sufficient by Ethical Committee of Pediatric Department, Faculty of Medicine, Zagazig University. And informed written consent was obtained in every case from their legal guardians.

\section{Funding}

The authors declare that they didn't receive any financial support from agencies or others.

\section{Conflict of interest}

No

Acknowledgements

We would like to thank all patients and their family members for their valuable contributions to the study. 